\title{
Conf-931054--3
}

UCRL-JC-114845

PREPRINT

\section{Electrostatic Reduction of Particulates for Laser Resistant Hafnia Coatings}

\author{
Mark D. Miller, Robert Chow, Gary E. Loomis
}

This paper was prepared for submittal to the Laser-Induced Damage in Optical Materials

October 27-29, 1993

Boulder, Colorado

\section{December 1993}

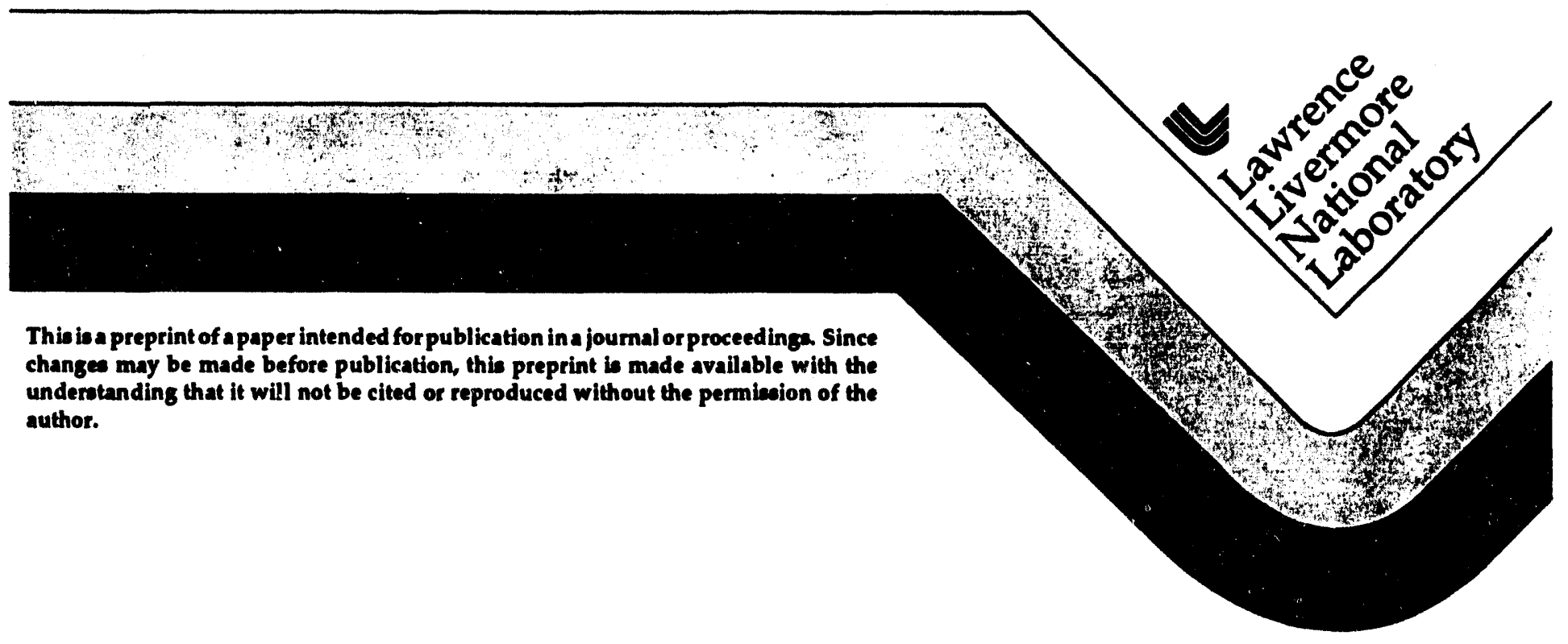


This document was prepared as an account of work sponsored by an agency of the United States Government. Neither the United States Government nor the University of California nor any of their employees, makes any warranty. express or implied, or assumes any legal liability or responsibility for the accuracy, completeness, or usefulness of any information, apparatus, product, or process disclosed, or represents that its use would not infringe privately owned rights. Reference herein to any specific commercial products. process, or service by trade name, trademark. manufacturer, or otherwise, does not necessarily constitute or imply its endorsement, recommendation. or favoring by the United States Government or the University of California. The views and opinions of authors expressed herein do not necessarily state or reflect those of the United States Government or the University of California. and shall not be used for advertising or product endorsement purposes. 


\title{
Electrostatic Reduction of Particulates for Laser Resistant Hafnia Coatings
}

\author{
Mark D. Miller, Robert Chow, Gary E. Loomis \\ University of California, Lawrence Livermore National Laboratory \\ P.O. Box 808, L-340 Livermore, CA 94551 USA
}

\begin{abstract}
We have reduced by $50 \%$ particulate defect density of hafnia coatings deposited onto silicon substrates through the use of electric fields, physical barriers and deposition rate. In an effort to reduce the number of hafnia $\left(\mathrm{HFO}_{2}\right)$ particulates deposited onto silicon wafers, parallel plate electrodes were placed on either side of the evaporant plume. The particulate level was determined as the deposition rate was varied from $0.75 \mathrm{~A} / \mathrm{sec}$ to $12 \mathrm{~A} / \mathrm{sec}$. Then, parallel plate electrodes were placed on either side of the plume as a way of electrostatically deflecting hafnia particulates away from the substrates. Later a single plate electrode was used in conjunction with a physical barrier placed over the hearth. The results of our study indicate that minimal defects occur when a parallel plate electric field is applied in conjunction with a fast deposition rate. Using a screen as a physical barrier, and/or a single electrode had little or no effect. This data may be useful in the manufacture of multilayer optical coatings with high laser damage thresholds.
\end{abstract}

\section{INTRODUCTION}

Particulate reduction in thin film deposition systems has long been of interest to researchers searching for higher quality, higher damage threshold coatings. This is especially true with recent advances in high power laser applications. Guenther ${ }^{1}$ has suggested a direct correlation between the number of particulates and the failure rate of a high reflector (HR) coating. It has been argued that the laser conditioning process, the procedure to enhances the laser damage threshold of coatings, could well originate from one or more of these particulates. ${ }^{2}$

Many schemes for particulate reduction have been devised. Tatsumi et. al. ${ }^{3}$ used a high voltage $(-6 \mathrm{kV})$ tantalum electrode to electrostatically deflect silicon particulates away from the substrate in an electron beam system. Their results show a complete elimination of particulates (from $35 / \mathrm{cm}^{2}$ to zero $/ \mathrm{cm}^{2}$ ) at this voltage. They suggest that the larger, slower moving particulates pick up an electric charge and after doing so, are deflected away from the substrate onto the side of the chamber. Venkatesan et. al." used a high speed velocity filter $(3,000 \mathrm{rpm})$ to deflect slower moving oxide particulates before they could reach the substrate while Letts et. al..$^{5}$ found controlling power, gas flow, and pressure during the entire deposition process though feedback control drastically improved their coatings by a plasma process.

All of the referenced data shows some level of particulate reduction. Little work has been done, however, on particulate reduction of oxides deposited using an electron beam evaporation system. Since most high laser damage threshold $\mathrm{HRs}$ are produced by evaporating $\mathrm{HfO}_{2}$ (hafnia) onto substrates using an e-beam system, we have chosen to investigate the reduction of hafnia particulates in an e-beam system.

\section{REDUCTION OF PARTICULATES IN HAFNIA COATINGS}

Using the concepts that particulates are slower moving, more likely to be charged, and physically larger than their atomic counterparts, we have attempted to configure our deposition system in such a way as to minimize the number of particulates deposited onto a substrate.

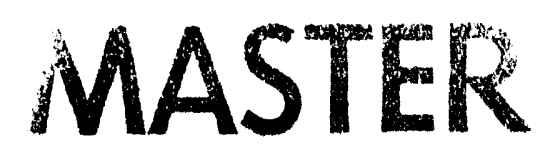

DISTRIBUTION OF THIS DOCUMENT IS UNLIMITED<smiles></smiles> 
A series of four experiments was carried out in an attempt to reduce the number of particulates in $\mathrm{HFO}_{2}$ coatings. First, a single deflection electrode was used to try to deflect away the charged particulates. When this produced a null results, a dual-electrode system was used. This was followed by a rate study. Then we concluded with the integration of both rate and dual electrode configuration.

All work was done in a $70 \mathrm{~cm} \times 70 \mathrm{~cm} \times 90 \mathrm{~cm}(1 \times \mp \times$ h) chamber with a conventional Sloan Electron Beam evaporator and a liquid- $\mathrm{N}_{2}$ cyropanel diffusion pump. An oxygen back flow of 5 ecc/min was maintained at all times. The wafer was planetated about the chamber during the runs. Base pressure was in the $10^{-7}$ Torr decade while run pressure was in the $10^{-4}$ Torr decade.

\subsection{Single Flectrode Study}

Following the work of Tatsumi et. al. a Si wafer was placed $50 \mathrm{~cm}$ from the $\mathrm{HfO}_{2}$ source. The distance from the $\mathrm{HfO}_{2}$ source to the single Ta deflection electrode was $6 \mathrm{~cm}$. High voltage could be applied to the deflection electrode using a high voltage DC power supply. A voltage of 0 to $-5 \mathrm{kV}$ was applied to the deflection electrode. This produced an electric field strength of about 4-6 X $10^{4} \mathrm{kV} / \mathrm{m}^{2}$. The hafnia films were deposited on a $3^{n}$ Si test wafers. A thin $(7000 \AA) \mathrm{HFO}_{2}$ layer was deposited on the wafer at a rate of $7 \mathrm{Asec}$ and ambient temperature. (Temperature typically went from $25^{\circ} \mathrm{C}$ to $90^{\circ} \mathrm{C}$ during the course of a run.) The acceleration voltage of the electron beam evaporator was $6 \mathrm{kV}$ and the emission current was about $200 \mathrm{~mA}$. Hafnia particulates were counted using an optical microscope and appear as black specs on an otherwise yellow surface.

The results of the single-electrode experiment (FIG. 1) show that within experimental error the electric field had no effect in reducing the number of $\mathrm{HfO}_{2}$ particulates deposited onto the wafer.

Hafnia Particulates

vs.

Single Negative Electrode Bias

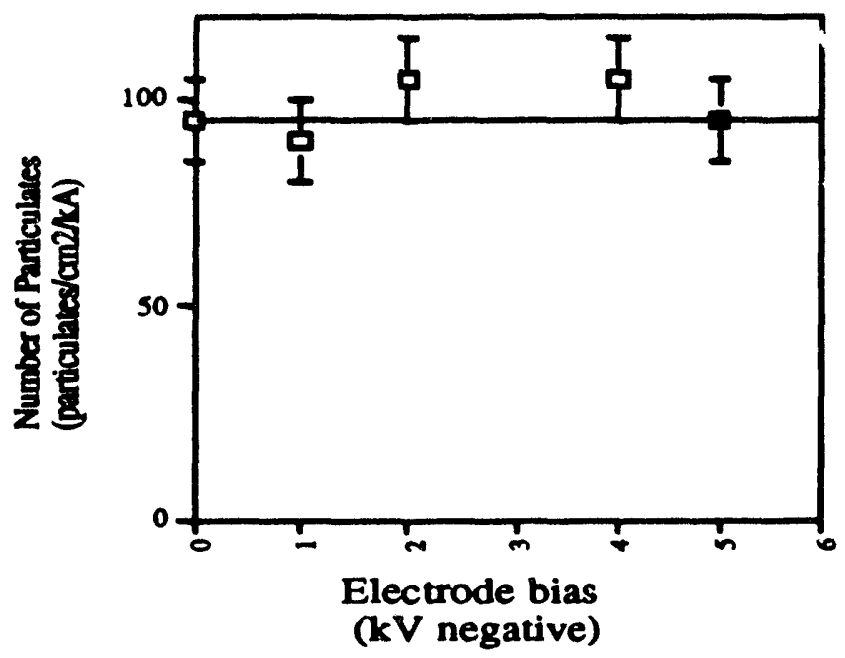

FIG. 1. Null results of particle reduction using a single deflection electrode.

\subsection{Double Electrode Study}

Following the null results of the single-electrode experiment, we attempted to increase the electric field strength within the plume area. This was accomplished by placing a positively charged stainless steel screen on the opposite side of the hearth from the Ta deflection electrode (FIG. 2). The positive bias was 
varied from 0 to $+3 \mathrm{kV}$ while the negative bias was varied from 0 to $-5 \mathrm{kV}$. All other factors were held constant with respect to the single electrode experiment.

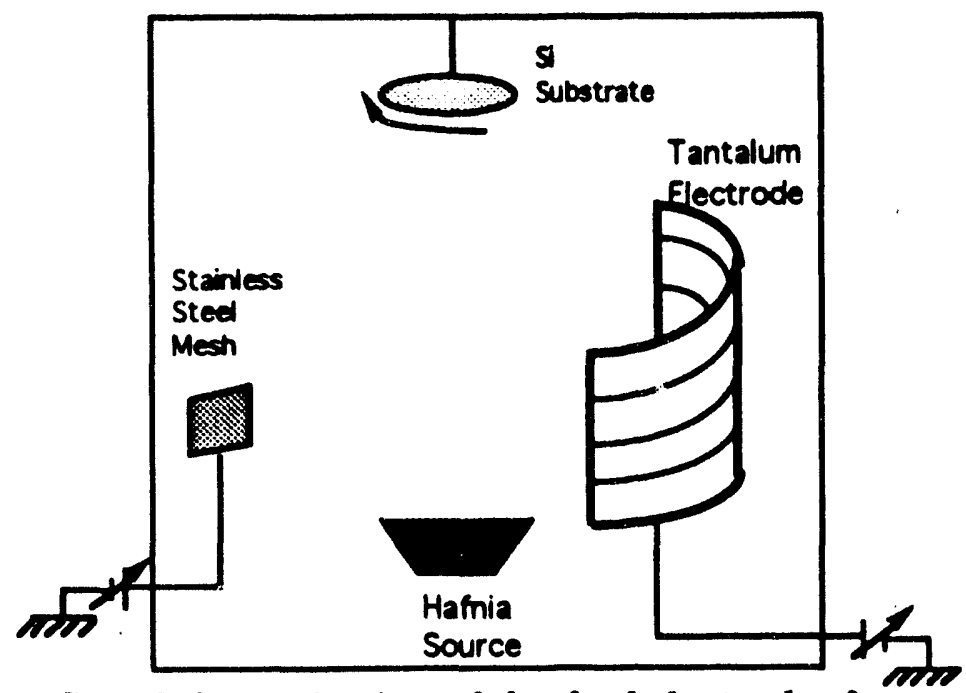

FIG. 2. Schematic view of the dual electrodes for particle reduction.

Results of this dual-electrode setup are shown in FIG. 3. The increase in field strength had an effect on particulate reduction.

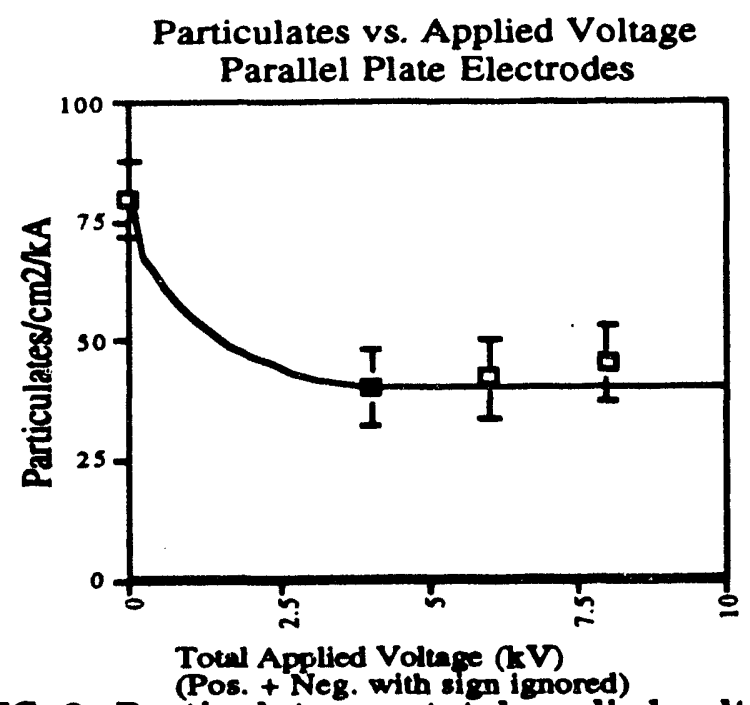

FIG. 3 Particulates vo total applied voltage. Total voltage is defined as the net voltage acroes both electrodes.

\subsection{Rate Study}

In this study, deposition rate was varied from $2 \AA \mathrm{sec}$ to $12 \mathrm{Asec}$ as determined by a rate monitor and verified using a contact profilometer. The increase in rate was accomplished by increasing the emission current while keeping the electron acceleration voltage constant at $6 \mathrm{kV}$. All other parameters were kept constant with respect to the procedures outlined in Sections 2.1 and 2.2 of this paper. No voltage was applied to either electrode. 
The results of this study are shown in FIG. 4. Clearly an inverse relationship between deposition rate and the number of particulates deposited on the Si wafer exists. At this time, however, no investigation into the quality or composition of the $\mathrm{HfO}_{2}$ films deposited at their corresponding rates has been undertaken.

\section{Particulates vs. Deposition Rate}

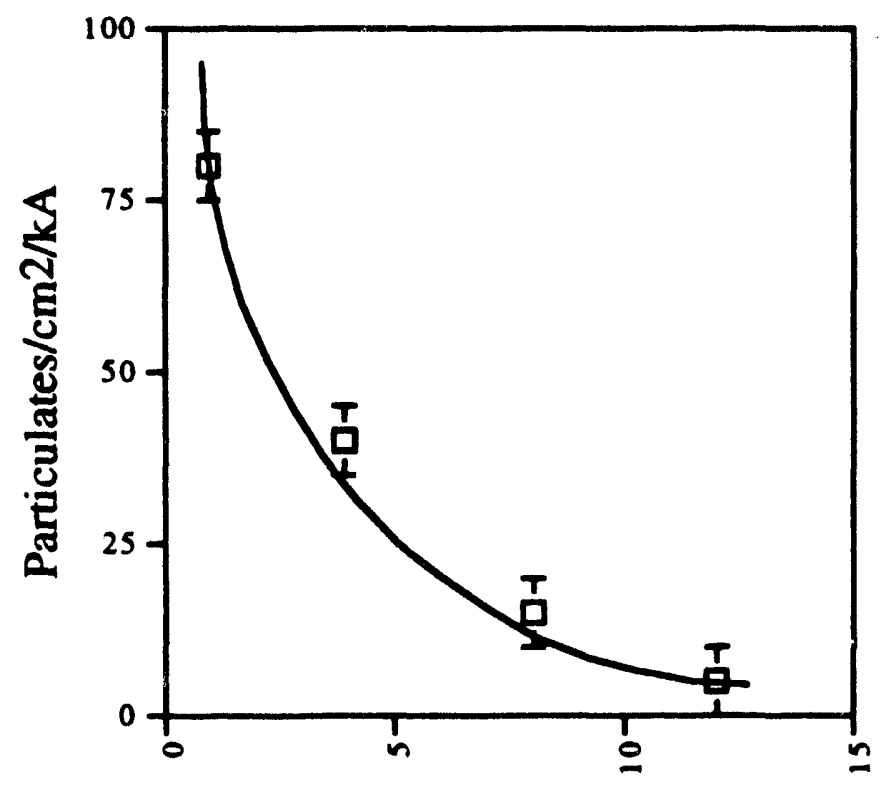

Rate in Angstroms/Sec

FIG. 4. Particulawas v8. Deposition rate for a Hafnia coating.

2.4 Combined dual electrode, high evaporation rate study

Finally, in an attempt to combine the benefits of both a dual electrode system and a high evaporation rate, the positively charged stainless steel screen was placed horizontally over the hearth and biased from +1 to $+3 \mathrm{kV}$, while the Ta deflection electrode was again biased from 0 to $-5 \mathrm{kV}$.

The purpose of the horizontal screen was twofold. First, the lines of electrostatic force remain directed across the plume, rather than diverging out into the vacuum chamber from the Ta electrode as in the single-electrode study. Second, because it acts as a physical mass filter, we can increase the evaporation rate at the source while still sustaining a low deposition rate (high oxygen/effluent impingement ratio) at the substrate. Results shown in FIG. 5 exhibit the particulate reduction trend also seen in FIG. 3 and FIG. 4. 


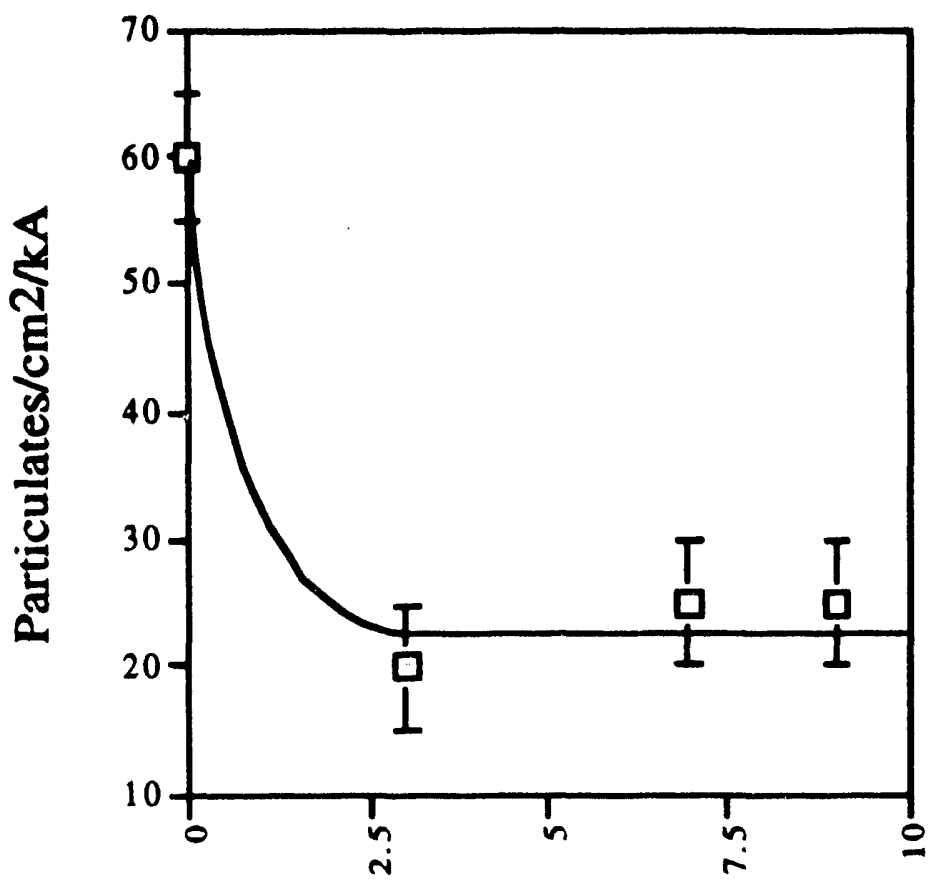

Total Voltage (kV)

FIG. 5 Particulates vs. Total electrode voltage. This series run with a high evaporation rate through a horizontal electrode. Deposition rate $=24 \mathrm{~A}$ sec.

\section{Conclusion}

Through the manipulation of electrostatic fields and deposition rate, we have been able to reduce the number of $\mathrm{HfO}_{2}$ particulates by over $50 \%$. We determined that the oxide particulates do not respond to a gingle electrode generated electrostatic field. The particulates do respond, however, to a dual electrode generated field if the positive electrode is placed close to the source. Perhaps the more electrostatically intense field makes it more likely that the larger, slower moving particles will contact an electron and become charged. After becoming charged, the particulate would be swept away by electrostatic attraction/repulsion.

Deposition rate has a large effect on the number of particulates deposited on the substrate. As the evaporation rate increases, the number of particulates decreases markedly. It is possible that the high energy required to produce these high deposition rates may also result in mors atomic metal and less atomic oxide being deposited onto the wafer. This would adversely affect the quality of the $\mathbf{H R}$.

A dual electrode system, with a positively biased screen placed horizontally over the source allows for both an increase in evaporation rate and an increase in the electrostatic fields of force. Using this apparatus, we have been able to reduce the number of particulates from $60 / \mathrm{cm}^{2}$ to $25 / \mathrm{cm}^{2}$, a decrease of $40 \%$. 


\section{Further work}

Investigation into the quality and characteristics of a $\mathrm{HfO}_{2}$ layer deposited at high deposition rates (12 $\mathrm{A} / \mathrm{sec}$ ) need to be undertaken. If this proves promising, then a $\mathrm{HrO}_{2} / \mathrm{SiO}_{2}$ multilayer should be manufactured and damage tested.

\section{Acknowrledoments}

Our thanks to Dave Sanders, Janet Conrad, Mark Kozlowski, support members of the Vacuum Process Group at Lawrence Livermore Lab and all of the members of our Monday Morning Defect Reduction Group.

Work performed under the auspices of the U.S. Department of Energy by the Lawrence Livermore National Laboratory under Contract W-7405-Eng-48.

\section{References}

1 K.H. Guenther, "Experimental observation and computer simulation of the mirostructure of vapor deposited thin films," Laser Induced damage in optical materials:1983, NBS Spec. Publ. 688, 393-406, 1983.

2M. C. Staggs, M. Balooch, M. R. Kozlowski, and W. J. Seikhaus, "In situ atomic force microscopy' of laser-conditioned and laser-damaged $\mathrm{HfO}_{2} / \mathrm{SiO}_{2}$ dielectric mirror coatings," Laser-induced damage in optical materials: 1991, eds. H. E., Bennett, L. L. Chase, A. H. Guenther, B. E. Newnam, and M. J. Soileau, SPIE vol. 1624, 375-385.

3T. Tatsumi, H. Hirayama, N. Aizaki, "Si particle density reduction in Si molecular beam epitaxy using a deflection electrode," Appl Phys. Lett., 54(7), 629-631, 1989.

4 T. Venkatesan, X.D. Wu, R. Muenchausen, A. Pique, "Pulsed laser deposition: future directions," MRS Bulletin, Feb. 1992, 54-58.

5 S.A. Letts, D.W. Myers, L.A. Witt, "Ultrasmooth plasma polymerized coatings for laser fusion targets," J. Vac. Sci. Technol., 19(3), 739-742, Sept./Oct. 1981. 


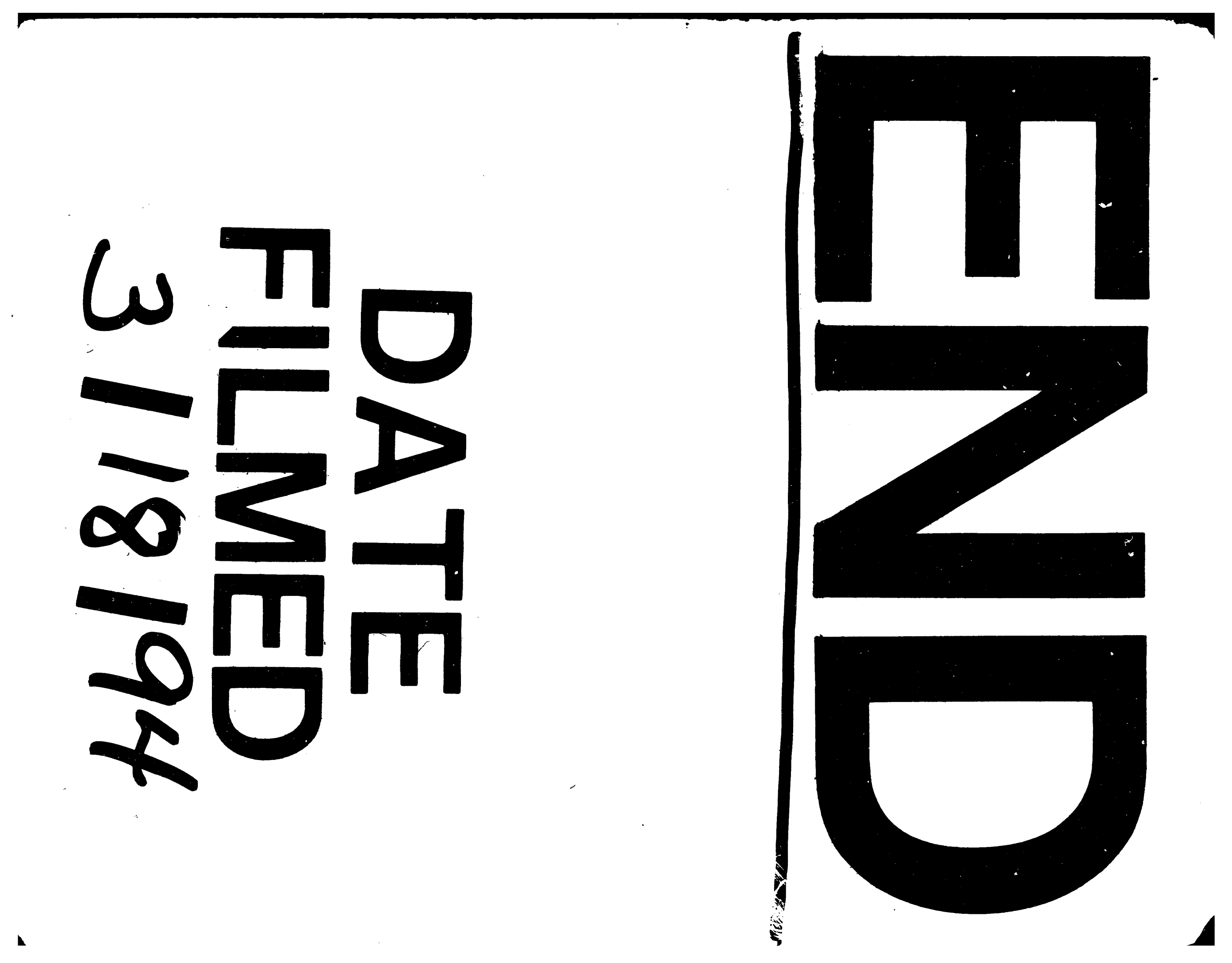



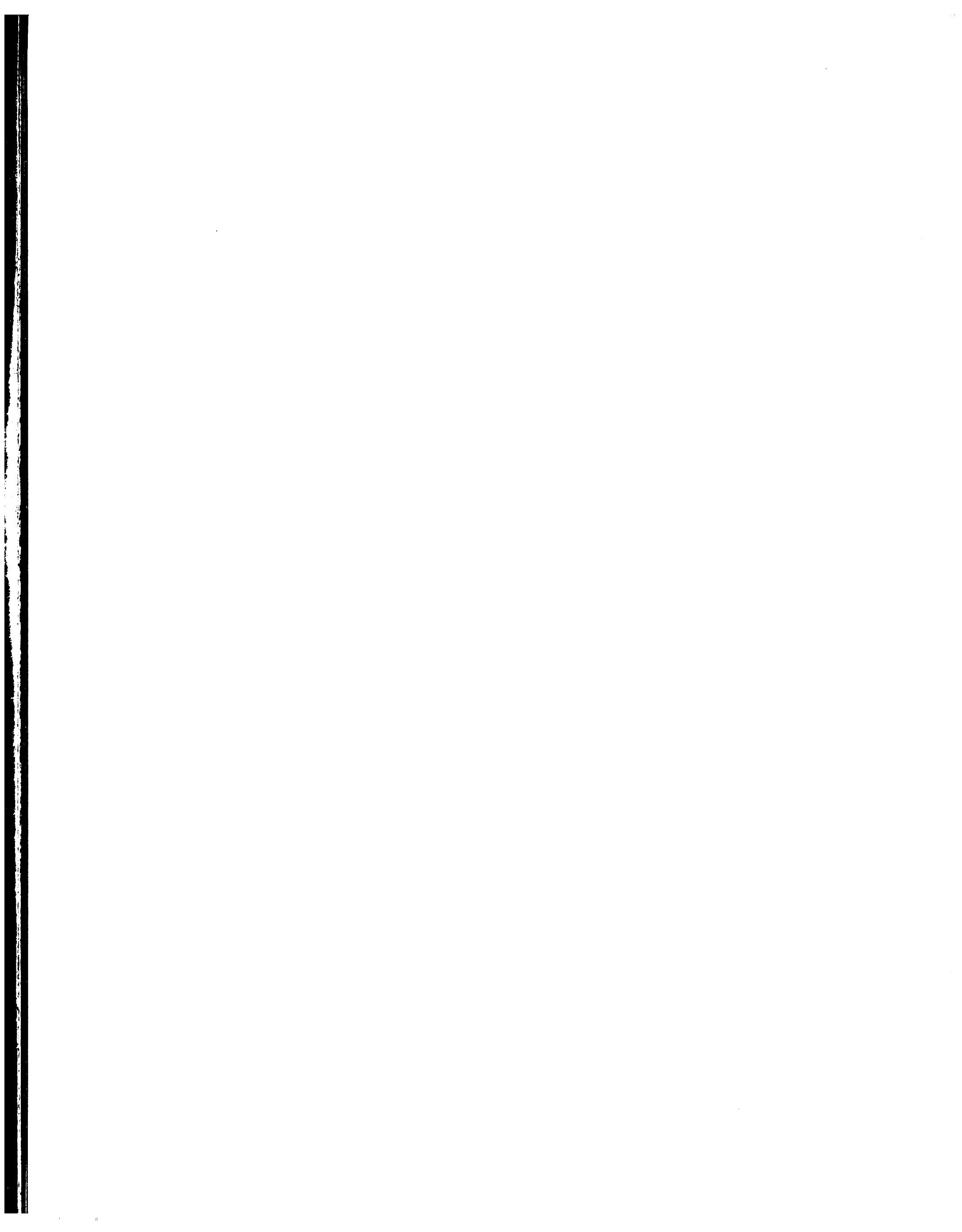